\title{
El deber legal de conservación, la ITE y el IEE: nuevos instrumentos normativos para el impulso de la conservación y la rehabilitación edificatoria
}

\author{
The legal duty of conservation, the ITE and the IEE: the deployment of new \\ regulatory instruments supporting buildings' conservation and upgrading \\ in Spain
}

E. de Santiago $^{(*)}$, I. González ${ }^{(* *)}$

\section{RESUMEN}

Este trabajo presenta los resultados del análisis comparado de la normativa estatal y autonómica, así como de las ordenanzas municipales, relacionadas con el deber legal de conservación, la Inspección Técnica (ITE) y el Informe de Evaluación de Edificios (IEE). Aunque se constata que, en los últimos años, se han generalizado estos instrumentos y que ya no solamente comprenden la evaluación del estado de conservación, sino también de la accesibilidad y la eficiencia energética, todavía falta un cierto recorrido conceptual para terminarlos de articular correctamente con los contenidos actuales del deber de conservación, la LOE y el CTE, así como para que estos instrumentos puedan impulsar realmente, más allá de la estricta conservación, la mejora de la calidad del parque edificado residencial español.

Palabras clave: Deber de conservación, Inspección Técnica de Edificios (ITE), Informe de Evaluación de Edificios (IEE), Rehabilitación.

\section{ABSTRACT}

This paper presents the results of the comparative analysis of the national, regional and local regulatory frameworks related to the legal duty of conservation, the Buildings' Technical Inspection (ITE) and the Buildings' Assessment Report (IEE). Although it confirms that these instruments have been widely assumed in Spain, and that they no longer only include the assessment of the conservation status, but also of buildings' accessibility and energy efficiency, there is still a certain conceptual gap to be filled in order to articulate them correctly with the current contents of the legal conservation duty and with the terminology of the LOE and the CTE, as well as to understand their role in the promotion, beyond the strict conservation, of the voluntary upgrading of the Spanish existing housing stock.

Keywords: Legal duty of conservation, Buildings' Technical Inspection (ITE), Buildings' Assessment Report (IEE), Buildings' upgrading.

(*) Ministerio de Fomento (España).

(*) ETSAM, Universidad Politécnica de Madrid (España).

Persona de contacto/Corresponding author: edesantiago@fomento.es (E. de Santiago)

ORCID: http://orcid.org/oooo-0oo2-1867-7867 (E. de Santiago); http://orcid.org/oooo-ooo2-6790-0252 (I. González)

Cómo citar este artículo/Citation: De Santiago, E.; González, I. (2019). El deber legal de conservación, la ITE y el IEE: nuevos instrumentos normativos para el impulso de la conservación y la rehabilitación edificatoria. Informes de la Construcción, 71(554): e287. https://doi.org/10.3989/ic.63735

Copyright: (C) 2019 CSIC. Este es un artículo de acceso abierto distribuido bajo los términos de la licencia de uso y distribución Creative Commons Reconocimiento 4.0 Internacional (CC BY 4.0). 


\section{EL DEBER LEGAL DE CONSERVACIÓN: SU REGULACIÓN HASTA LA LEY 8/2013}

El deber de conservación, formulado como deber de ejecutar las obras necesarias para evitar daños a terceros, por la caída de un "edificio, pared, columna o cualquiera otra construcción que amenazase ruina" está recogido desde 1889 en el artículo 389 del Código Civil, si bien su formulación más conocida se debe a la Ley de 12 de mayo de 1956 sobre régimen del suelo y ordenación urbana, en cuyo artículo 168 se establece que "los propietarios de terrenos, urbanizaciones particulares, edificaciones y carteles deberán mantenerlos en condiciones de seguridad, salubridad y ornato públicos", añadiéndose en el artículo 169 que "los Ayuntamientos [...] podrán también ordenar, por motivos turísticos o estéticos, la ejecución de obras de conservación y de reforma en fachadas o espacios visibles desde la vía pública [...]" y que "las obras se ejecutarán a costa de los propietarios si se contuvieren en el límite del deber de conservación que les corresponde, y con cargo a fondos de la entidad que lo ordene cuando lo rebasaren para obtener mejoras de interés general".

Las ideas básicas aquí formuladas (la conservación como deber de mantener los edificios en condiciones de seguridad, salubridad y ornato -sin definir en qué consisten-, las obras de mejora por motivos turísticos o culturales, el límite económico del deber legal) se incorporaron en la Ley de Suelo de 1975 como parte de los deberes inherentes a la propiedad del suelo, y desde aquí se reprodujeron prácticamente sin modificación alguna en todas las leyes autonómicas, así como en las sucesivas estatales. Así, más de 50 años después, en la formulación dada por el Real Decreto Legislativo 2/2008, de 20 de junio, por el que se aprueba el Texto Refundido de la Ley de Suelo (artículo 9: Contenido del derecho de propiedad del suelo: deberes y cargas), sólo se había añadido la dedicación a usos no incompatibles con la ordenación territorial y urbanística, y una referencia a la accesibilidad, expresándose del siguiente modo: "el derecho de propiedad de los terrenos, las instalaciones, construcciones y edificaciones, comprende [...] los deberes de dedicarlos a usos que no sean incompatibles con la ordenación territorial y urbanística; conservarlos en las condiciones legales para servir de soporte a dicho uso y, en todo caso, en las de seguridad, salubridad, accesibilidad y ornato legalmente exigibles; así como realizar los trabajos de mejora y rehabilitación hasta donde alcance el deber legal de conservación. Este deber constituirá el límite de las obras que deban ejecutarse a costa de los propietarios, cuando la Administración las ordene por motivos turísticos o culturales, corriendo a cargo de los fondos de ésta las obras que lo rebasen para obtener mejoras de interés general".

En 1999 se produjo una novedad significativa, que fue la aprobación de la primera Ley de Ordenación de la Edificación en España (Ley 38/1999, de 5 de noviembre, en adelante LOE), superando así -como se reconocía en la Exposición de Motivos- el contraste entre la tradicional y exhaustiva regulación urbanística y "la falta de una configuración legal de la construcción de los edificios, básicamente establecida [hasta ese momento] a través del Código Civil y de una variedad de normas cuyo conjunto adolece de serias lagunas en la ordenación del complejo proceso de la edificación". La principal innovación de la LOE con relación al aspecto que nos ocupa fue la referencia introducida en el artículo 3 (Requisitos básicos de la edificación) estableciendo que "con el fin de garantizar la seguridad de las personas, el bienestar de la sociedad y la protección del me- dio ambiente, los edificios deberán proyectarse, construirse, mantenerse y conservarse de tal forma que se satisfagan los requisitos básicos siguientes", clasificados como relativos a la funcionalidad, a la seguridad (estructural, en caso de incendio y de utilización), y a la habitabilidad (incluyendo la salubridad).

\section{EL NACIMIENTO DE LAS PRIMERAS INSPECCIONES DE LOS EDIFICIOS Y SU EVOLUCIÓN EN LA LEGISLACIÓN AUTONÓMICA HASTA 2011}

La primera norma urbanística que reguló en España la inspección periódica de edificios fue la Ley urbanística valenciana (Ley 6/1994), cuyo artículo 87 determina que "los propietarios de toda edificación catalogada o de antigüedad superior a cincuenta años deberán promover, al menos, cada cinco años, una inspección, a cargo de facultativo competente, para supervisar su estado de conservación. Dicho facultativo consignará los resultados de su inspección expidiendo un certificado que describa los desperfectos apreciados en el inmueble, sus posibles causas y las medidas prioritarias recomendables para asegurar su estabilidad, seguridad, estanqueidad y consolidación estructurales o para mantener o rehabilitar sus dependencias en condiciones de habitabilidad o uso efectivo según el destino propio de ellas. [...]"

Claramente inspiradas por esta regulación, otras 12 Comunidades Autónomas fueron incorporando la ITE a su legislación hasta 2011. En cuanto a ayuntamientos, hasta ese momento tan sólo tenían aprobada una ordenanza de Inspección Técnica de Edificios (ITE) 51 municipios en toda España, careciendo de ella 28 capitales provinciales.

\section{EL INTENTO ABORTADO DE LA INSPECCIÓN TÉCNICA PERIÓDICA ESTATAL DE 2011}

En el año 2011, en plena crisis económica y financiera -que había provocado el desplome de la construcción de viviendas y la urbanización de suelo características de la burbuja inmobiliaria española 1997-2007-, el Gobierno aprobó la Ley 2/2011, de 4 de marzo, de Economía Sostenible, que contemplaba algunas medidas para la recuperación del sector de la construcción mediante una serie de reformas centradas en el impulso a la rehabilitación urbana. Pocos meses después, el Real Decretoley 8/2011, de 1 de julio, continuó avanzando en esta dirección e introdujo por vez primera en una norma estatal -según se explica en la propia Exposición de Motivos- "la inspección técnica de edificios, estableciendo su obligatoriedad y sus requisitos esenciales", para lo cual se "dota a este instrumento, ya existente en la mayoría de las leyes urbanísticas en vigor [12 en aquel momento], de la uniformidad necesaria para garantizar unos contenidos que ayuden a conseguir la adaptación del parque de viviendas existente a los criterios mínimos de calidad exigidos”. En base a ello, el artículo 21 establecía que "los edificios con una antigüedad superior a 50 años [salvo que las Comunidades Autónomas fijasen otra distinta], destinados preferentemente a uso residencial [y situados en municipios mayores de 25.000 habitantes] [...], deberán ser objeto, en función de su antigüedad, de una inspección técnica periódica que asegure su buen estado y debida conservación", evaluando "la adecuación de estos inmuebles a las condiciones legalmente exigibles de seguridad, salubridad, accesibilidad y ornato" y determinando "las obras y trabajos de conservación que se requieran para mantener los inmuebles en el estado legalmente exigible, y el tiempo señalado al efecto". 
Si bien se dejaba un cierto margen para lo que fijasen las Comunidades Autónomas y los municipios (periodicidad, etc.), la Disposición transitoria Segunda establecía un Calendario según el cual todos los edificios obligados debían haberse sometido a la inspección antes de 2015 .

\section{LA SISTEMATIZACIÓN DE LOS 3 NIVELES DEL DEBER DE CONSERVACIÓN EN LA LEY 8/2013}

Apenas un par de años después, la Ley 8/2013, de 26 de junio, de rehabilitación, regeneración y renovación urbanas, se propuso formular -esta vez de manera exhaustiva- un nuevo marco normativo estatal que favoreciera la reconversión del tradicional enfoque expansionista del urbanismo español hacia la ciudad consolidada, potenciando la rehabilitación edificatoria, la regeneración y renovación urbanas. Para ello, proponía eliminar las numerosas trabas existentes y crear nuevos mecanismos específicos que hicieran posible y viable dicha reconversión, contribuyendo no sólo a la reactivación económica, sino también al fomento de la calidad, la sostenibilidad y la competitividad del medio urbano. Entre otras muchas aportaciones, se modificó el artículo $9^{1}$ del Real Decreto Legislativo 2/2008 del TR de la Ley de Suelo, mediante el cual -según consta en la Exposición de Motivos- "[...] se completa la regulación del deber legal de conservación, para sistematizar los tres niveles que ya, de conformidad con la legislación vigente, lo configuran: un primer nivel básico o estricto, en el que el deber de conservación conlleva, con carácter general, el destino a usos compatibles con la ordenación territorial y urbanística y la necesidad de garantizar la seguridad, salubridad, accesibilidad y ornato legalmente exigibles [artículo15.1.b]. Además, con carácter particular [en las edificaciones], el deber legal de conservación también contiene [artículo 17.3.a] la necesidad de satisfacer [textualmente en el artículo 17.3.a: "con carácter general" $]$ los requisitos básicos de la edificación, establecidos en el artículo 3.1 de la Ley 38/1999, de 5 de noviembre, de Ordenación de la Edificación, con lo que se dota de mayor coherencia a la tradicional referencia de este deber a la seguridad y a la salubridad, sin que el cumplimiento de estos requisitos signifique, con carácter general, la aplicación retroactiva del Código Técnico de la Edificación, aprobado por el Real Decreto 314/2006, de 17 de marzo, a la edificación construida con anterioridad a la entrada en vigor del mismo.

Un segundo nivel [artículo 17.3.b], en el que el deber de conservación incluye los trabajos y obras necesarios para adaptar y actualizar progresivamente las edificaciones, en par- ticular las instalaciones, a las normas legales que les vayan siendo explícitamente ${ }^{3}$ exigibles en cada momento. No se trata de aplicar con carácter retroactivo la normativa, sino de incluir en este deber las obligaciones que para la edificación existente explícitamente vaya introduciendo la normativa del sector con el objetivo de mantener sus condiciones de uso, de acuerdo con la evolución de las necesidades sociales.

Y un tercer nivel [artículo15.1.c], en el que se define con mayor precisión y se perfila más específicamente, el carácter de las obras adicionales incluidas dentro del propio deber de conservación, por motivos de interés general, desarrollando lo que la Ley de Suelo definió como "mejora». Se distinguen así dos supuestos: los tradicionales motivos turísticos o culturales, que ya forman parte de la legislación urbanística autonómica, y la mejora para la calidad y sostenibilidad del medio urbano, que introdujo la Ley 2/2011, de 4 de marzo, de Economía Sostenible, y que puede consistir en la adecuación parcial, o completa, a todas o a alguna de las exigencias básicas establecidas en el ya citado Código Técnico de la Edificación. En ambos casos, la imposición del deber requerirá que la Administración, de manera motivada, determine el nivel de calidad que deba ser alcanzado por el edificio [es decir, hasta qué nivel deben cumplirse las exigencias del CTE], para cada una de las exigencias básicas a que se refiera la imposición del mismo y su límite [económico] se mantiene en los mismos términos que ya contiene la legislación en vigor 4 [...]"

\section{LA REGULACIÓN ESTATAL DEL IEE EN LA LEY 8/2013 Y LA SENTENCIA 143/2017 DEL TRIBUNAL CONSTITUCIONAL}

La Ley 8/2013 también reguló el Informe de Evaluación de los Edificios (IEE) en su Título I (artículo 4,5 y 6), incluyendo, además, una Disposición Transitoria $\left(1^{\mathrm{a}}\right)$ y una Disposición Final $\left(18^{\mathrm{a}}\right)$ relacionadas con el mismo. Dado que la regulación de la ITE del RD 8/2011 había sido recurrida como inconstitucional por la Generalitat de Cataluña ${ }^{5}$, anticipándose al fallo, la Ley 8/2013 intentó -como señala la Exposición de Motivos- superar "algunas de sus insuficiencias. Entre ellas, la que lo identificaba plenamente con la Inspección Técnica de Edificios regulada por las Comunidades Autónomas y por algunos Ayuntamientos [...]”, o el plazo, considerado como "inasequible para los más de 3 millones de viviendas afectadas". Es por ello que planteó el IEE como un instrumento, en principio -y como su propio nombre indica-, sólo informativo, para "asegurar la calidad y sostenibilidad del

\footnotetext{
Tras la refundición del TR de la Ley de Suelo (Real Decreto Legislativo 2/2008) y la Ley 8/2013, en el actualmente vigente Real Decreto Legislativo 7/2015, las modificaciones introducidas en el artículo 9 en 2013 han quedado distribuidas en los nuevos artículos 15.1 y 17 , por lo que a continuación se hace referencia a éstos, tal y como están vigentes en la actualidad.

2 Esta precisión es fundamental, pues remite al cumplimiento sólo "con carácter general" de los "requisitos" (LOE) -equiparando por tanto en este nivel general a toda la edificación: la existente y la nueva-, pero no de las "exigencias" (CTE), a las que se refiere en términos de adecuación parcial o completa en el tercer nivel del deber.

3 Caso de los ajustes razonables en materia de accesibilidad, por ejemplo.

4 En su redacción vigente del DL 7/2015, de 30 de octubre, por el que se aprueba el Texto Refundido de la Ley de Suelo y Rehabilitación Urbana, "El deber legal de conservación constituye el límite [económico] de las obras que deban ejecutarse a costa de los propietarios" [art. 15.2] y "se establece en la mitad del valor actual de construcción de un inmueble de nueva planta, equivalente al original, en relación con las características constructivas y la superficie útil, realizado con las condiciones necesarias para que su ocupación sea autorizable o, en su caso, quede en condiciones de ser legalmente destinado al uso que le sea propio" [art.15.3]. Cuando las obras ordenadas para obtener mejoras de interés general superen dicho límite, el exceso correrá a cargo de los fondos de la Administración que las ordene [art. 15.2].

5 Finalmente, el Tribunal Constitucional falló en 2016, mediante la Sentencia 5/2016, de 21 de enero de 2016, declarando la inconstitucionalidad y nulidad de los arts. 21 y 22, de la DA $3^{\mathrm{a}}$ y de las DT $1^{\mathrm{a}}$ y $2^{\mathrm{a}}$ del RDL 8/2011, pues "se trata, sin lugar a dudas, de la regulación de una técnica o instrumento propiamente urbanístico, [...], así como comprobar el cumplimiento del deber de conservación que corresponde a los propietarios. Son, pues, preceptos que se incardinan con claridad en la materia de urbanismo, es competencia de las Comunidades Autónomas [...]”.
} 
parque edificado, así como obtener información que le permita orientar el ejercicio de sus propias políticas", desvinculándolo de la obligación de realizar obras para subsanar las deficiencias detectadas y "sin prejuzgar las concretas medidas de intervención administrativa que deban poner en marcha las Administraciones competentes".

La principal innovación conceptual del IEE era su triple contenido (artículo 4), que debía comprender no sólo ya la evaluación del estado de conservación del edificio, sino también "la evaluación de las condiciones básicas de accesibilidad universal y no discriminación de las personas con discapacidad para el acceso y utilización del edificio, de acuerdo con la normativa vigente, estableciendo si el edificio es susceptible o no de realizar ajustes razonables para satisfacerlas", y la certificación de la eficiencia energética del edificio.

La aprobación de la Ley 8/2013 suscitó nuevamente un conflicto competencial con algunas CCAA, resolviéndose en algunos casos mediante Comisiones Bilaterales, y presentando el Consejo de Gobierno de la Generalitat de Cataluña un recurso de inconstitucionalidad (5493-2013) en relación con estos y otros preceptos, cuyo fallo emitió el Tribunal Constitucional el pasado 14 de diciembre de $2017^{6}$. El fallo, en su parte correspondiente al IEE, señala que "el precepto interfiere también en el modo en que las Comunidades Autónomas controlan el cumplimiento del deber de conservación[...], pues el Estado no está competencialmente habilitado para regular técnicas o instrumentos urbanísticos dirigidos a verificar el cumplimiento de esos deberes de los propietarios" e indica que "en conclusión, salvo lo dispuesto en el artículo 4.1, el Estado no ostenta título competencial alguno que le permita imponer la evaluación del estado de conservación de los edificios y del cumplimiento de las condiciones de accesibilidad que, junto a la certificación de eficiencia energética, integran el contenido del informe de evaluación de edificios en los términos y con el contenido previstos en la de la Ley 8/2013”.

Por tanto, en estos momentos en relación con el IEE sólo queda vigente a nivel estatal el apartado 1 del artículo 29 del RD 7/2015:

\section{“Artículo 29. El Informe de Evaluación de los Edificios.}

1. Los propietarios de inmuebles ubicados en edificaciones con tipología residencial de vivienda colectiva podrán ser requeridos por la Administración competente, de conformidad con lo dispuesto en el artículo siguiente, para que acrediten la situación en la que se encuentran aquéllos, al menos en relación con el estado de conservación del edificio y con el cumplimiento de la normativa vigente sobre accesibilidad universal, así como sobre el grado de eficiencia energética de los mismos".

\section{LA REVISIÓN DEL MARCO NORMATIVO POSTERIOR A LA LEY 8/2013}

La aprobación de la Ley 8/2013 produjo una nueva generación de normas autonómicas y ordenanzas municipales: por un lado, regularon por primera vez el IEE muchos ayuntamientos y las cuatro CCAA que todavía carecían de normativa en esta materia (Baleares, Navarra, Murcia y Cantabria) $\mathrm{y}$, por otro, se revisaron en profundidad muchas normas autonómicas y ordenanzas municipales previas a la legislación estatal de 2013, para adaptarlas a las novedades introducidas por ésta. A fecha de enero de 2018, todas las CCAA tienen aprobada ya normativa al respecto, excepto Galicia ${ }^{8}$. Finalmente, de las dos ciudades autónomas, Ceuta no tiene todavía aprobada ordenanza, mientras que Melilla la aprobó en el año 2013.

\section{SOBRE LA CONSERVACIÓN EN LA ITE O EL IEE}

Dado que la evaluación de la conservación fue el origen de las primeras inspecciones técnicas, todas las CCAA que la han regulado incluyen este aspecto (también así lo hizo Galicia, en el artículo 200 de la Ley 9/2002, actualmente derogada). Pero habitualmente, ni la regulación autonómica ni las ordenanzas municipales han entrado a definir en detalle el contenido preciso del concepto de conservación que debe evaluarse (es decir, el "cómo"), limitándose a relacionar (en los correspondientes textos normativos o modelos de informe aprobados) los sistemas, elementos constructivos, o instalaciones cuyo estado de conservación debe examinarse (es decir, el "qué"). Normalmente, estos son: estructura y cimentación, fachadas y medianeras, cubiertas y azoteas y -todo lo más -las instalaciones comunes de fontanería y de saneamiento del edificio. Un ejemplo representativo de este amplio conjunto de normas autonómicas o municipales podría ser la Ordenanza de Albacete de 2012, que en su artículo 19.1 señala que las actas de la inspección deben describir: "a) el estado de la estructura y cimentación; b) el estado de las fachadas interiores, exteriores, medianerías del edificio, en especial de los elementos los que pudieran suponer un peligro para la vía pública, como petos de terrazas, placas, etc... e incluso elementos superpuestos (rótulos, instalaciones o similares); c) el estado de cubiertas y azoteas; $y, d)$ el estado de las redes generales de fontanería y saneamiento del edificio”.

En muy parecidos términos se desarrolla el contenido de la parte de conservación del modelo de IEE propuesto por el RD estatal 233/2013, que sólo añade el estado de conservación de las instalaciones comunes de electricidad.

Entre los pocos ejemplos que proponen avances en este sentido hay que mencionar en primer lugar, por su carácter pionero, la regulación castellano-leonesa. Originalmente, el artículo 317 del Decreto 22/2004, por el que se aprueba el Reglamento de Urbanismo de Castilla y León, desarrollaba el contenido del "Certificado e informe de inspección" en términos relativamente poco novedosos, limitándose a añadir -además del tradicional listado de los elementos a revisar- estructura, cimentación, fachadas exteriores, interiores y medianeras, cubiertas y azoteas- los "voladizos, marquesinas, antenas y demás elementos susceptibles de desprendimiento, así como las redes de sanea-

\footnotetext{
${ }^{6}$ Sentencia 143/2017, de 14 de diciembre de 2017. Recurso de inconstitucionalidad 5493-2013. Interpuesto por el Consejo de Gobierno de la Generalitat de Cataluña en relación con diversos preceptos de la Ley 8/2013 (BOE 17 de enero de 2018).

7 Dado que el RDL 7/2015 incorporó literalmente los artículos referidos al IEE de la Ley 8/2013, renumerándolos como art. 29, 30 y DT $2^{\mathrm{a}}$ y DF $1^{a}$, el artículo 4.1 de la Ley 8/2013 se corresponde con el 29.1 del RDL 7/2015.

8 Si bien esta Comunidad había introducido en 2002 la Inspección Periódica de Construcciones la derogó en 2016, entendiéndose aplicada la regulación estatal entonces vigente. No obstante, a fecha de enero de 2018, 9 de los 10 municipios de más población de Galicia tienen aprobada su correspondiente ordenanza.
} 
miento y distribución de agua, gas y energía eléctrica en baja tensión". Más innovadora resultaba la mención -en el mismo artículo- de prestar especial atención "a los elementos vinculados directamente a la estabilidad, consolidación estructural, estanqueidad y en general a la seguridad del edificio y de las personas", pues si bien continuaba refiriéndose a los elementos a inspeccionar (el "que"), lo hacía por primera vez en relación con el contenido de la conservación (el “cómo”).

Esta idea se observa mucho más claramente en las sucesivas modificaciones del mismo artículo introducidas primero por el Decreto 10/2013, de 7 marzo -anterior, pues al RD estatal 233/2013 y a la Ley 8/2013-, por el que se modifica el Reglamento de Urbanismo de Castilla y León en relación con la Inspección Técnica de Construcciones; y, después, por el Decreto 6/2016, de 3 marzo, por el que se modifica el Reglamento de Urbanismo de Castilla y León para su adaptación a la Ley 7/2014 castellano-leonesa de medidas sobre rehabilitación, regeneración y renovación urbana, y sobre sostenibilidad, coordinación y simplificación en materia de urbanismo.

En la primera modificación de 2013, se introdujeron dos novedades en el artículo 317.bis. La primera fue la incorporación de varios apartados, que exigían evaluar -además de las condiciones tradicionales de seguridad- "las condiciones de salubridad, ornato público y habitabilidad" (aclarando que "entre las condiciones de habitabilidad se entenderán incluidas las de accesibilidad"), además del "cumplimiento de los deberes de uso y dotación de servicios" [remitiendo a su regulación precisa en los artículos 15 y 16 del Reglamento de Urbanismo], valorando si, a criterio del técnico inspector el edificio cuenta con los servicios mínimos exigibles y se destina al uso inicialmente previsto", así como el del cumplimiento de la normativa sectorial $\mathrm{u}$ otras condiciones que pudieran ser aplicables a cada tipo de edificio. Ello supone la ampliación de la frontera conceptual de la conservación más allá de la seguridad: primero a la salubridad y al ornato -cerrando así el círculo de la tríada de conceptos asociados al deber de conservación en la normativa urbanística desde 1956-, y, en una segunda vuelta, a la habitabilidad, incluyendo dentro de ésta la accesibilidad. La otra novedad es el intento de definir de forma precisa el contenido de estas condiciones, vinculándolas con el tradicional deber de conservación propio de la normativa urbanística, mediante la remisión al artículo 19 del propio Reglamento donde se desarrolla éste 9 .

En la modificación del mismo artículo realizada en 2016 se avanza todavía más en esta precisión conceptual. Así, en el apartado referido a la seguridad, se la vincula ya no sólo con lo regulado en el artículo 19.2.a de la misma norma dedicado al deber de conservación, sino más significativamente, con los 3 requisitos de seguridad de la LOE: seguridad estructural, seguridad en caso de incendio y seguridad de utilización, cuyas definiciones recoge y transcribe íntegramente el articulado desde la LOE. La novedad fundamental está, por tanto, no sólo en extender el entendimiento de la seguridad -más allá de la estructural que venía siendo habitual en las inspecciones- a la de utilización y en caso de incendio, sino en establecer una vinculación terminológica inequívoca entre el término seguridad del deber de conservación propio de la normativa urbanística con los requisitos de la LOE, como plantea la legislación estatal.

Resulta mucho menos clara la vinculación entre los términos de habitabilidad y salubridad introducidos en 2013 con los requisitos básicos de la edificación de la LOE, siendo el resultado confuso si se examina con esta perspectiva, pues el artículo está empleando el término "habitabilidad" en su acepción tradicional propia de la normativa de vivienda ${ }^{10}(\mathrm{y}$ que, en la LOE, se denomina "funcionalidad": prueba de ello es que la vincule, como se hace en la misma LOE, con la accesibilidad), mientras que manifiesta una confusión entre la "salubridad" y lo que la LOE denomina propiamente requisito básico de "habitabilidad" (y que, en la LOE, incluye a la salubridad y estanquidad en el ambiente interior del edificio).

Esta vinculación directa entre los contenidos del deber de conservación que se ha de verificar mediante la ITE o el IEE y los requisitos básicos de la LOE está claramente formulada en la Ordenanza Tipo Reguladora del IEE aprobada como modelo por la Junta de Gobierno de la FEMP el 30 de julio de 2013. En ella se expresa que, a efectos de evaluar el estado de conservación de los edificios, el IEE deberá comprobar que -al menos- se satisfacen las "condiciones básicas de la edificación" de "seguridad estructural", "higiene, salud y protección del medio ambiente" (entre las que incluye "la protección frente a la humedad", "el suministro de agua", y "la evacuación de aguas"), así como la seguridad en las instalaciones comunes de electricidad del edificio. Si bien en lo cuantitativo las exigencias son bastante tradicionales -se trata de un modelo tipo de ordenanza, y por tanto, de un mínimo común denominador- y la única diferencia con una ordenanza clásica en este aspecto como la mencionada de Albacete es la referencia a las instalaciones comunes de electricidad, en lo cualitativo el salto conceptual es importante, pues no sólo se emplea la terminología propia de la LOE y el CTE, sino que se traslada literalmente a la ordenanza el enunciado preciso de cada uno de los requisitos básicos de la edificación que se exige evaluar y se recoge (artículo 10) que la evaluación del estado de conservación únicamente será favorable "cuando el edificio cumpla los requisitos básicos de la edificación en los términos establecidos en [...] la presente Ordenanza”.

Por último, cabe mencionar el caso de la Región de Murcia, que es la que exige una evaluación más amplia de la parte de conservación de su IEE (artículo 6 del Decreto 34/2015), incluyendo los siguientes aspectos: relativos a la seguridad (seguridad estructural, desalojo del edificio en caso de incendio, protección frente al riesgo de caídas, seguridad frente al riesgo de impacto, iluminación ade-

\footnotetext{
9 Allí se definen del modo siguiente (más vinculado a la tradición histórica de uso de estos conceptos en la legislación urbanística que a la literalidad con respecto a los requisitos básicos de la edificación de la LOE): la salubridad como el "conjunto de las características higiénicas y sanitarias de los inmuebles y de su entorno que aseguran la salud de sus usuarios y de la población" y la habitabilidad como el "conjunto de las características de diseño y calidad de las viviendas y de los lugares de trabajo y estancia, de los inmuebles donde se sitúan y de su entorno, que satisfacen las exigencias de calidad de vida de sus usuarios y de la sociedad".

${ }^{10}$ Lo que conoce como "normativa o condiciones básicas de habitabilidad", que incluye tanto la cédula de habitabilidad como las condiciones de diseño de las viviendas, por ejemplo, la Orden de 29 de febrero 1944 por la que se regulan las condiciones higiénicas mínimas que han de reunir las viviendas.
} 
cuada), a la salubridad (estanqueidad, suministro de agua evacuación de aguas residuales y pluviales), accesibilidad y ornato.

También desde el punto de vista conceptual queda clara la vinculación entre la regulación murciana y los requisitos básicos de la edificación o las exigencias del CTE, utilizándose referencias directas y la misma terminología. Es significativo, sin embargo, que, en alguno de los aspectos, en lugar de la referencia general al requisito básico (como hacía la regulación castellano-leonesa con respecto a la seguridad, o la ordenanza de la FEMP) el articulado exija sólo comprobar determinadas condiciones. Por ejemplo, en lugar de referirse genéricamente a la seguridad frente al riesgo de caídas, que englobaría todos los aspectos de la exigencia básica SUA 1 del CTE, se limita a establecer que "en las zonas comunes se comprobará que los desniveles con una diferencia de cota mayor que 55 cm están protegidos con barreras de protección y que las barreras de protección y barandillas son suficientemente resistentes. Asimismo, se comprobará que los pavimentos no presentan piezas sueltas ni resaltos que puedan provocar caídas”.

En cualquier caso, y desde el punto de vista conceptual, hay que destacar el esfuerzo realizado por estas últimas normas mencionadas para establecer un puente entre la normativa urbanística y la de edificación.

\section{SOBRE LOS EFECTOS DE LA ITE O EL IEE Y SU RELACIÓN CON EL DEBER DE CONSERVACIÓN}

Si bien las primeras inspecciones técnicas de edificios surgieron con el objeto de "supervisar" (artículo 87 Ley 6/1994, de la Comunidad Valenciana) o "determinar" (artículo 138 Ley 2/1998 de Castilla La Mancha) el estado de conservación de los mismos, en las primeras regulaciones autonómicas no quedaba claramente establecida su relación conceptual con el "deber de conservación". Aunque la vinculación era evidente y quedaba implícita, no se presentaba la inspección como instrumento de "acreditación" o "justificación del cumplimiento" de este deber, y - lo que a efectos prácticos es más importante- tampoco se formulaba la obligatoriedad de realizar obras para subsanar las deficiencias detectadas. Un avance en esta vinculación conceptual es el ejemplo de la Ordenanza municipal de Zaragoza de 2002, en cuyo artículo 32.1 establece que "la obligación formal de acreditar el cumplimiento del deber de conservación de las edificaciones [...] se verificará mediante la obtención por el propietario del inmueble de un informe con dictamen, expedido por técnico competente, designado por el mismo, donde se conste por escrito la realización de la inspección y visado por el colegio oficial correspondiente, con el contenido, forma y plazos previstos a este capítulo".
Ambas ideas se expresan ya claramente en el artículo 22 del DL 8/2011, que introdujo por primera vez la ITE a nivel estatal ${ }^{11}$ : "cuando de la inspección realizada resulten deficiencias, la eficacia del documento acreditativo de la misma, a los efectos de justificar el cumplimiento del deber legal de conservación a que se refiere el artículo 9 de la Ley de Suelo, quedará condicionada a la certificación de la realización efectiva de las obras y los trabajos de conservación requeridos para mantener el inmueble en el estado legalmente exigible, y en el tiempo señalado al efecto". Se establecía ya, por tanto, una relación directa y unívoca entre la ITE, como instrumento de comprobación del cumplimiento del deber de conservación, y las obras para subsanar las deficiencias, como parte inherente de este deber por parte de los propietarios.

En la actualidad, la gran mayoría de la normativa autonómica exige la subsanación de las deficiencias, y generalmente remite a los ayuntamientos para su control. Un ejemplo prototípico es el caso asturiano. Como en prácticamente todas la CCAA y ordenanzas municipales ${ }^{12}$, en Asturias, la calificación del IEE en relación con el estado de conservación ${ }^{13}$ (artículo 8 del Decreto 29/2017) puede ser: favorable (si todos los grupos constructivos son informados favorablemente) o desfavorable (cuando al menos uno de los grupos haya sido informado desfavorablemente), en cuyo caso (artículo 9) el IEE debe describir las deficiencias, hacer un prediagnóstico de sus causas y sus posibles soluciones, indicar los plazos para su subsanación y la procedencia o no de medidas urgentes para garantizar la seguridad del edificio, de sus usuarios o de terceros. El artículo 9.2 establece nítidamente que "en caso de que el Informe sea desfavorable los propietarios estarán obligados a adoptar las medidas recogidas en el mismo para corregir las deficiencias advertidas”, dentro del plazo establecido al efecto. Finalizado dicho plazo, y, una vez corregidas las deficiencias, los propietarios deberán remitir a la administración un anexo al IEE donde se relacionen las obras ejecutadas (adjuntando, si procede, la licencia municipal y el certificado final de obra). Dicho anexo, en su caso, le dará al Informe carácter favorable y permitirá su registro con esta calificación ${ }^{14}$.

Entre las ordenanzas municipales que también recogen esta idea cabe mencionar el modelo de Ordenanza Tipo Reguladora del IEE aprobado por la FEMP (1). Si bien el modelo de IEE del RD 233/2013 -incorporado por esta ordenanza como propio- pide indicar las deficiencias detectadas que deben ser subsanadas (especificando si condicionan -por sí mismas, o en combinación con otras- la valoración global del estado de conservación de cada uno de los elementos del edificio analizados -cimentación, estructura, fachadas, cubiertas, etc.como desfavorable, aportando información sobre la localización de cada una de estas deficiencias, su descripción, las pruebas y ensayos realizados, etc.) no recoge ni el enunciado de su obligatoriedad ${ }^{15} \mathrm{ni}$, mucho menos, un procedimiento de

\footnotetext{
${ }^{11}$ Precisamente esta cuestión motivó el recurso presentado por parte de la Generalitat catalana ante el Tribunal Constitucional, fallando a su favor mediante Sentencia 5/2016, de 21 de enero de 2016.

12 Una excepción es el caso catalán, donde hay toda una compleja gama de matices, que más adelante se comentan, o los de las ordenanzas de Zaragoza y Huesca. En estos dos últimos casos, no se admiten a trámite aquellos informes que no tengan resultado favorable, no entendiéndose pasada la Inspección hasta que no se hayan realizado las obras para subsanar las deficiencias. Desde el punto conceptual tiene pleno sentido que, si los propietarios tienen el deber de conservación, la Administración no admita un informe desfavorable que manifieste que lo incumplen, si bien desde el punto de vista práctico no está claro que este procedimiento sea más efectivo que el convencional.

${ }^{13}$ Los apartados de accesibilidad y eficiencia energética solo dan lugar a informe desfavorable cuando supongan algún incumplimiento de la normativa aplicable al edificio.

${ }_{14}$ De modo que, como el caso de Zaragoza y Huesca, las inspecciones finalmente habrán de ser favorables.
} 
control de dichas obras. La Ordenanza de la FEMP, por tanto, completa este aspecto y establece en su artículo 12 un procedimiento muy semejante al que suele ser habitual en muchos ayuntamientos: "a la vista del informe desfavorable, el Ayuntamiento podrá comunicar a la propiedad para que en el plazo de dos meses proceda a solicitar las obras para subsanar las deficiencias detectadas en la parte de conservación del Informe de Evaluación realizado, con la advertencia de que en el caso de incumplimiento, se adoptarán las medidas sancionadoras y sustitutorias previstas en la normativa de aplicación”. Hay varios municipios que, además, exigen un "compromiso de ejecución" previo a la solicitud de la licencia, por ejemplo, en el caso de la ordenanza de Algeciras (artículo 6.1) se establece que "los propietarios deberán mediante un Compromiso de Ejecución, solicitar en el plazo de dos meses la licencia correspondiente para acometer las obras necesarias recogidas en el Informe de Inspección”.

Sin embargo, en varias CCAA, sobre todo en las de normativa más antigua, la obligación de realizar obras para la subsanación de las deficiencias no es tan clara, o la normativa autonómica no establece un procedimiento reglado para su control efectivo. En los casos de Andalucía (artículo 156 de la Ley 7/2002), Aragón (artículo 260 del Decreto 1/2014) y Extremadura (artículo 164 de la Ley 15/2001), cuya regulación en este sentido es casi idéntica, sólo se dice que las inspecciones deben describir "los desperfectos y las deficiencias apreciados, sus posibles causas y las medidas recomendadas, en su caso, con fijación de un orden de prioridad, para asegurar la estabilidad, la seguridad, la estanqueidad y la consolidación estructurales", pero no se va más allá del carácter de recomendaciones ni se establece un procedimiento de control administrativo de las obras necesarias para subsanarlas.

En Canarias tampoco se hace referencia a la obligatoriedad de realizar obras para subsanar las deficiencias de conservación detectadas, si bien sí se mencionan "las órdenes de ejecución que pueda dictar la Administración en aquellos supuestos en los que deba garantizarse la seguridad, salubridad y ornato de las edificaciones" (artículo 269.5 de la Ley 4/2017).

Caso diferente es el la Región de Murcia, donde el artículo 5.10 del Decreto 34/2015 señala que "los Informes de Evaluación de los Edificios tendrán exclusivo carácter informativo, sin perjuicio de las eventuales responsabilidades civiles o penales derivadas del estado de conservación del edificio y del ejercicio por las Administraciones públicas competentes de sus potestades de control de los deberes legales de conservación de los edificios, que se ejercerán mediante la realización de la correspondiente inspección del edificio por el técnico municipal competente y el dictado, en su caso, de la correspondiente orden de ejecución de obras, de conformidad con lo establecido en la normativa de ordenación urbanística aplicable".

También es reseñable por su excepcionalidad el procedimiento determinado por la regulación catalana. La Ley 18/2007 establece en su artículo 28.6 que, efectivamente y como principio, "las carencias respecto a las condiciones exigibles suponen la adopción de medidas correctoras", estableciéndose para ello un procedimiento completo que se desarrolla en el Decreto 67/2015. La principal peculiaridad del mismo es que -a diferencia de otras Comunidades, donde son los Ayuntamientos los encargados de la gestión directa de las inspecciones o del IEE (comprobación de la realización de las obras de subsanación de deficiencias, emisión de órdenes de ejecución, incluso ejecución subsidiaria, etc. ${ }^{16}$ )en Cataluña esta tarea corresponde fundamentalmente a la Generalitat ${ }^{17}$. Por otra parte, en lugar de la típica calificación del resultado de la inspección como favorable o desfavorable, en el caso de Cataluña, una vez presentado el informe de la ITE, la Administración debe emitir, en función de las deficiencias detectadas (que son calificadas en diversos grados: muy graves, graves, importantes o leves ${ }^{18}$ ), un "certificado de aptitud", que debe contener las advertencias necesarias para la ejecución de las obras, y que se emite en los siguientes términos (artículo12): "resolución denegatoria de aptitud" (si el edificio presenta deficiencias calificadas como graves o muy graves sin que se hayan ejecutado las medidas cautelares propuestas), "apto cautelarmente" (si el edificio tuviese deficiencias graves o muy graves, habiendo resuelto no obstante las situaciones de riesgo mediante la ejecución de las medidas cautelares correspondientes), "apto provisional" (si el edificio presenta deficiencias calificadas como importantes), "apto" ( si el edificio no presenta deficiencias, o éstas son calificadas como leves). En los casos segundo y tercero, el certificado de aptitud solo acredita que la propiedad cumple el deber de conservación y rehabilitación cuando se hayan realizado las obras necesarias que hayan hecho desaparecer las deficiencias calificadas como graves, muy graves o importantes. Respecto al seguimiento de la ejecución de las obras, el artículo 14 establece todo un complejo sistema en función de la diferente vigencia que se otorga al certificado de aptitud, según la calificación de éste. Con carácter general, su

${ }_{15}$ Como no podía ser de otra forma, pues dado el recurso de inconstitucionalidad contra el DL 8/2011, la regulación estatal evitó establecer esta vinculación.

${ }^{16}$ Por ejemplo, en Extremadura el art. 2 del Decreto 73/2017 señala: "en el ámbito de la Comunidad Autónoma de Extremadura, la Administración competente para requerir el Informe de Evaluación de los Edificios a los propietarios de los inmuebles obligados a disponer del mismo de conformidad con el Real Decreto Legislativo 7/2015 [...] serán los Ayuntamientos donde radiquen dichos edificios".

${ }_{17}$ "[...] corresponde a la Administración de la Generalidad el impulso y el fomento de las inspecciones técnicas, la implementación de un sistema de información para el mantenimiento del fichero común de inspecciones técnicas de edificios de viviendas de la Agencia de Vivienda de Cataluña, la recepción de las inspecciones realizadas y el otorgamiento de los certificados de aptitud, sin perjuicio de lo que indica el artículo 13, así como el control del parque inspeccionado y la renovación de las inspecciones" (art. 16 del Decreto 67/2015). El art. 13 mencionado contempla la posibilidad de que puedan emitir el certificado de aptitud "las administraciones locales en los supuestos de que hayan aprobado programas u ordenanzas locales [...]".

${ }^{18}$ La gradación de las deficiencias se establece en el art. 9: son muy graves las que representan un riesgo inminente y generalizado para la estabilidad del edificio y la seguridad de las personas, y requieren una intervención inmediata (que puede incluir el desalojo, la declaración de ruina, la toma de medidas cautelares o la ejecución de obras); graves, las que representan un riesgo para la estabilidad o la seguridad de determinados elementos del edificio o graves problemas de salubridad (requieren en una primera fase la adopción de medidas cautelares y en una segunda la ejecución de obras para subsanarlas); importantes, las que no representan riesgo inminente, pero afectan a la salubridad y funcionalidad (siendo necesarias obras más allá del simple mantenimiento); y leves, las que hacen necesaria la realización de trabajos de mantenimiento preventivo y/o corrector para evitar su agravamiento. 
vigencia en edificios sin deficiencias o con deficiencias leves es de 10 años; de 6, en edificios con deficiencias importantes; y de 3, en edificios de viviendas con deficiencias graves o muy graves con medidas cautelares ejecutadas. Además se establecen otras provisiones complementarias, por ejemplo: "en el supuesto de deficiencias importantes, la vigencia del certificado de aptitud queda condicionada al hecho de que cada dos años se efectúe una verificación técnica que incluya la visita de un profesional técnico al edificio para examinar los elementos con deficiencias importantes y la elaboración de un informe para hacer constar que aquellas deficiencias no han pasado a la calificación de grave o muy grave, salvo el supuesto en que se hayan iniciado las obras para repararlas" (artículo 14).

Finalmente, también la normativa autonómica del País Vasco (artículo 12 del Decreto 241/2012), en lugar de que sea el propio informe el que establezca libremente el plazo de intervención, obliga a que el Dictamen de la ITE diferencie la naturaleza de los tipos de intervención, encuadrando ésta dentro de unas categorías o grados normalizados (inmediata, muy urgente, urgente, necesaria a medio plazo y/o de mantenimiento), en base a los cuales se fija un plazo máximo de actuación ${ }^{19}$.

\section{RECAPITULACIÓN Y CONCLUSIONES}

Como se ha visto, en los últimos años y tras diversas vicisitudes legales, prácticamente todas las CCAA españolas se han dotado de un marco normativo más o menos desarrollado que establece la obligación - al menos para los propietarios de viviendas ubicadas en edificios de tipología residencial colectiva- de realizar una ITE o IEE en la que se evalúe ya no sólo -como ocurría en las primeras regulaciones- el estado de conservación del edificio, sino también el cumplimiento de la normativa vigente sobre accesibilidad universal, así como el grado de eficiencia energética. La figura siguiente presenta estos resultados, de forma sintética:

\begin{tabular}{|c|c|c|c|c|c|c|}
\hline & 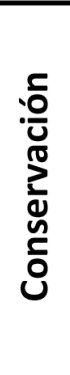 & 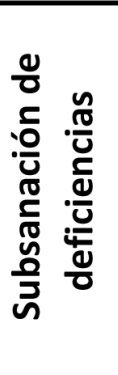 & 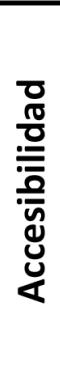 & 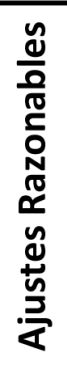 & 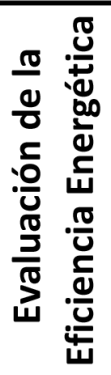 & 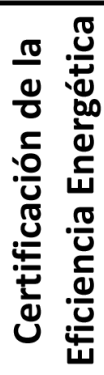 \\
\hline \multicolumn{7}{|l|}{ Andalucía } \\
\hline \multicolumn{7}{|l|}{ Aragón } \\
\hline \multicolumn{7}{|l|}{ Baleares } \\
\hline \multicolumn{7}{|l|}{ Canarias } \\
\hline \multicolumn{7}{|l|}{ Cantabria } \\
\hline \multicolumn{7}{|l|}{ Castilla-La Mancha } \\
\hline \multicolumn{7}{|l|}{ Castilla y León } \\
\hline \multicolumn{7}{|l|}{ Cataluña } \\
\hline \multicolumn{7}{|l|}{ Extremadura } \\
\hline Galicia & $(*)$ & $(*)$ & $(*)$ & $(*)$ & $(*)$ & $(*)$ \\
\hline \multicolumn{7}{|l|}{ La Rioja } \\
\hline \multicolumn{7}{|l|}{ Comunidad de Madrid } \\
\hline \multicolumn{7}{|c|}{ Región de Murcia } \\
\hline \multicolumn{7}{|c|}{ Comunidad Foral de Navarra } \\
\hline \multicolumn{7}{|l|}{ País Vasco } \\
\hline \multicolumn{7}{|l|}{ Principado de Asturias } \\
\hline Comunidad Valenciana & & & & & & \\
\hline
\end{tabular}

Figura 1. Resumen de los contenidos del IEE o ITE en las CCAA. Leyenda: Verde oscuro: regulación autonómica más exigente o innovadora que la Ley 8/2013. Verde claro: regulación autonómica en los mismos términos que la Ley 8/2013. Amarillo: regulación autonómica parcial. Rojo: no existe regulación autonómica o no se recoge este aspecto. (*): En revisión. Fuente: Elaboración propia.

\footnotetext{
19 Para las intervenciones inmediatas (aquellas con riesgo de colapso de elementos o con riesgo inminente para personas o bienes) se da un plazo de 24 horas para tomar las medidas pertinentes (desalojo, apuntalamiento, etc.). Para las muy urgentes (asociadas a daños importantes en el edificio o en sus elementos, con riesgo a corto plazo) se establece un plazo de 3 meses. Para las urgentes (asociadas a deficiencias graves, que puedan llevar a la degradación de un elemento de forma progresiva) se dan 12 meses. Para las calificadas como necesarias a medio plazo (asociadas a deficiencias puntuales, que si no se corrigen puede degenerar en un proceso patológico de mayor envergadura) se permite aplazarlas más de un año. Finalmente, las de mantenimiento, sólo se proponen como el conjunto de operaciones y cuidados a efectuar periódicamente para prevenir el deterioro del edificio y mantenerlo en buen estado.
} 
Se ha analizado también cómo algunas normas han sabido articular bien la evaluación del estado de conservación con el cumplimiento de este deber, cuyos contenidos -en principio, definidos en la legislación urbanística- han sido también reformulados en paralelo, vinculándolos a la normativa de edificación (LOE y CTE), articulación conceptual de notable importancia que, como se ha visto, no todas las normas analizadas sobre la ITE o el IEE han comprendido en su plena dimensión.

Si bien queda aún un cierto recorrido conceptual en la normativa vigente para terminar de articular correctamente la ITE o el IEE con los contenidos del deber del conservación y con la terminología de la LOE y el CTE, en el plano práctico (y salvo en aquellas CCAA donde aún no están implantados estos instrumentos), puede decirse que en la gran mayoría de CCAA y municipios españoles cuentan ya con un instrumento para inspeccionar los edificios y exigir a los propietarios el cumplimiento del deber de conservación.

Pero más allá del estricto deber de conservación planteado como meras reparaciones o como subsanación de las deficiencias detectadas, conviene comenzar a plantearse la conservación preventiva (2). En este sentido, el artículo 8 del Decreto 67/2015 de Cataluña contiene dos ideas interesantes: la propuesta de recomendaciones "para un mantenimiento y conservación correctos del edificio, así como la periodicidad de estas acciones", así como el establecimiento de que éstas deban formar parte de las instrucciones que contiene el Libro del Edificio, ampliando por tanto a los edificios existentes la obligación legal de disponer de éste en los edificios de nueva construcción. En cuanto a ordenanzas municipales, la de Jaén de 2012 contiene un Anexo I en el que propone un exhaustivo plan orientativo de revisiones básicas a realizar en los edificios, indicando las comprobaciones y operaciones de mantenimiento a realizar, así como sus plazos, para las instalaciones y para cada elemento o sistema constructivo.

El reto más importante planteado implícitamente por la Ley 8/2013 es la superación del estricto deber conservación (3) para avanzar hacia una rehabilitación más profunda que voluntariamente vaya mejorando la calidad del parque edificado y actualizando los requisitos de calidad que hoy exigen la sociedad actual y la regulación europea. Esta es precisamente la idea que subyace en la inclusión dentro del IEE de los ajustes razonables en accesibilidad y de la certificación energética: la búsqueda de sinergias entre la conservación y otro tipo de obras de carácter voluntario, como la rehabilitación energética (5) siguiendo con el espíritu de las Directivas 2012/27/ UE y 2010/31/UE, y más en particular con el artículo 7 de esta última, en relación con la mejora de la eficiencia energética cuando se realicen "reformas importantes" en los edificios existentes ${ }^{20}$. En este sentido, cabe destacar por ejemplo la provisión del artículo 8.2 de la Ordenanza de Ferrol de 2015: "La certificación de eficiencia energética contendrá no solo la calificación energética del edificio, sino también las recomendaciones sobre las mejoras energéticas que podrían realizarse en términos de coste/beneficio y clasificadas dependiendo de su viabilidad técnica, económica y funcional y su impacto energético". O la del artículo 23.1.c de la ordenanza de Granada de 2015: "además, esta información también podrá servir para el establecimiento de medidas de mejora de la eficiencia energética de las edificaciones, sin que en ningún caso pueda tener efectos para el resultado, favorable o desfavorable, de la inspección”.

Si no se logran despertar estas sinergias (por ejemplo, colocar un aislamiento por exterior aprovechando la instalación de un andamio para picar y revocar una fachada con deficiencias) la conservación estricta puede convertirse incluso en enemiga, al retrasarla, de la rehabilitación profunda que necesita gran parte de nuestro parque inmobiliario (4). Para ello es necesario un cambio cultural no sólo en los propietarios, sino también en las administraciones responsables de la ITE o el IEE, y de los técnicos que lo realizan, superando su mera conceptualización como instrumento de policía urbanística o control burocrático del estado de conservación de los edificios, para convertirlo en una verdadera herramienta para la mejora de la calidad del parque edificado.

\section{REFERENCIAS}

(1) Campos Acuña, María Concepción (2016). "La Ordenanza de Rehabilitación Tipo de la FEMP. Un instrumento para el cumplimiento del deber de conservación”. En Práctica urbanística: Revista mensual de urbanismo, No. 138, págs. $148-156$.

(2) García González, Julián; Santiago Rodríguez, Eduardo de; Pérez Pérez, Iñaki; Enseñat Beso, José María; Durán Domínguez, Adelaida (2014). "Debate sobre el Informe de Evaluación del Edificio". En Cercha: Revista de los Aparejadores y Arquitectos Técnicos, No. 119, 2014, págs. 8-15.

(3) Menéndez Rexach, Ángel (2014). "El informe de evaluación de los edificios en la Ley 8/2013”. Ciudad y Territorio Estudios Territoriales, $\mathrm{N}^{\circ} 179$, págs. 63-74.

(4) Rodríguez Andión, Ramón J. (2004). "La inspección periódica de edificios como mecanismo de aseguramiento del deber de conservación: insuficiencia de la regulación actual”. Ciudad y Territorio Estudios Territoriales, No 139, págs. 173203.

(5) Sanchís Cuesta, Alberto; Serrano Lanzarote, Begoña (2015). "La Inspección Técnica de Edificios como herramienta de la mejora energética de la edificación existente”. En Informes de la Construcción, ISSN o020-0883, Vol. 67, N. ${ }^{\circ}$ Extra 1.

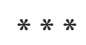

\footnotetext{
${ }_{20}$ Provisión ya incorporada a nuestro ordenamiento en el apartado 2.2.2.1 (Limitación de la demanda energética en edificios existentes) del documento DD-HE1 del CTE.
} 